\title{
A Bi-Objective Portfolio Optimization with Conditional Value-at-Risk
}

\author{
Bartosz Sawik*
}

\begin{abstract}
This paper presents a bi-objective portfolio model with the expected return as a performance measure and the expected worst-case return as a risk measure. The problems are formulated as a bi-objective linear program. Numerical examples based on 1000, 3500 and 4020 historical daily input data from the Warsaw Stock Exchange are presented and selected computational results are provided. The computational experiments prove that the proposed linear programming approach provides the decision maker with a simple tool for evaluating the relationship between the expected and the worst-case portfolio return.
\end{abstract}

Keywords: multi-criteria decision making, portfolio optimization, conditional value-at-risk, weighting approach, linear programming.

Mathematics Subject Classification: 91G10 - portfolio theory, 90C29 - multi-objective and goal programming, 90C90 - applications of mathematical programming, 90C05 - linear programming.

Revised: 15 December 2010.

\section{INTRODUCTION}

The portfolio problem, which involves computing the proportion of the initial budget that should be allocated in the available securities, is at the core of the field of financial management. A fundamental answer to this problem was given by Markowitz (1952, $1959,1991,1997)$ who proposed the mean-variance model which laid the basis of modern portfolio theory. In Markowitz's approach the problem is formulated as an optimization problem involving two criteria: the reward of portfolio, which is measured by the mean or expected value of return that should be maximized, and the risk of the portfolio, which is measured by the variance of return that should be minimized. In the presence of two criteria there is not a single optimal solution (portfolio structure), but a set of optimal portfolios, the so-called efficient portfolios, which trade-off between risk and return. Since the mean-variance theory of Markowitz, an enormous amount of papers have been published extending or modifying the basic model in three directions.

\footnotetext{
* Department of Applied Computer Science, Faculty of Management, AGH University of Science and Technology, Kraków, Poland, b_sawik@yahoo.com
} 
The first path goes to simplification of the type and the amount of input data. The second direction concentrates on the introduction of the alternative measure of risk. Finally, the third involves the incorporation of additional criteria and/or constraints (e.g. Anagnostopoulos et al. (2010)).

The overall process of selecting a portfolio is divided into two stages (Markowitz, 1952). The first stage starts with observation, experience and ends with beliefs about the future performances of available securities. The second stage starts with relevant beliefs about future performances and ends with the choice of portfolio. One type of rule concerning choice of portfolio is that the investor should maximize the capitalized value of future returns. The decision maker places all his funds in the security with the greatest discounted value. Investor diversify his founds among all those securities which give maximum expected return. If two or more securities have the same value, then any of these or any combination of these is as good as any other. However, the portfolio with maximum expected return is not necessarily the one with minimum risk. The law of large numbers will insure that the actual yield of the portfolio will be almost the same as the expected yield. There is a rate at which the investor can gain expected return by taking on risk measure, or reducing risk by giving up expected return (Ogryczak, 2000). In the classical Markowitz model future returns are random variables that can be controlled by the two parameters: a portfolio's efficiency calculated by the expectation, and a risk, which is measured with variance. The classical problem is formulated as a quadratic program with continuous variables and some side constraints. Bai et al. (2009a, 2009b) have developed a new bootstrap-corrected estimator of the optimal return for the Markowitz mean-variance optimization. Markowitz and van Dijk (2003) find that under certain conditions, the single-period mean-variance model provides a good approximation to multi-period expected utility maximization.

Although the original Markowitz model forms a quadratic programming problem, following Sharpe (1971), many attempts have been made to linearize the portfolio optimization procedure (for instance Speranza (1993)). The linear program solvability is very important for applications to real-life financial and other decisions where the constructed portfolios have to meet numerous side constraints. The examples of them are minimum transaction lots, transaction costs or mutual funds characteristics etc. The introduction of these features leads to mixed integer programming problems.

For some basic investment decision-making approaches, the decision maker may be restricted to choosing only one of a discrete number of alternatives. For other scenarios, a diversified portfolio comprised of a convex combination of two or more alternatives may be feasible and will often better balance risk and return. Sharpe (1971) stated that "if the essence of the portfolio analysis problem could be adequately captured in a form suitable for linear programming methods, the prospect for application would be greatly enhanced". Linear programming efforts the decision maker the opportunity to determine an optimal balance between risk and return for modeling portfolio optimization problems with diversification among alternatives.

There is a vast literature on portfolio selection devoted to the balancing of risk and return in financial markets. The most celebrated of these (as it was previously written) is the approach of Markowitz $(1952,1959,1991,1997)$ where a quadratic 
mean-variance model with risk measured by the covariance matrix of returns was developed. Konno and Yamazaki (1991) noted that the derivation of the covariance matrix can be cumbersome, attempting to solve a quadratic model has computational limitations in practice, and the optimal solution may consist of purchasing a large number of securities. They suggest employing linear objectives to alleviate these computational limitations. In spite of the fact that Sharpe (1963) developed a methodology for practical solution of the quadratic objective, many approaches have been taken to linearize the model. Sharpe $(1967,1971)$ and Stone $(1973)$ both showed how the quadratic model could be transformed to an equivalent model with a separable quadratic function making it much easier to solve with linear approximation approaches. Leung and Wong (2008) have developed a multivariate Sharpe ratio statistic to test the hypothesis of the equality of multiple Sharpe ratios.

Biglova at al. (2004) identified several other criteria for estimating portfolio theory risk that can be employed in LP models instead of the covariance risk measure of Markowitz (1952, 1959, 1991, 1997). Among these include Gini's mean absolute difference as incorporated by Yitzhaki (1982) resulting in a LP for constructing efficient portfolios. In their linear optimization model, Konno (1990) and Konno and Yamazaki (1991) employed absolute deviation rather than covariance to measure the risk. They solved a problem with 224 stocks over 60 months on a real-time basis and found results similar to that of the mean-variance model but requiring much less computational effort. Speranza (1993) generalized this approach using a risk function that is a linear combination of two semi-absolute deviations of return from the mean.

Ogryczak (2000) formulated and solved a multi-objective LP consisting of one objective for each time period and showed the mean-variance approach of Markowitz $(1952,1959,1991,1997)$, the absolute deviation approach of Konno and Yamazaki (1991), and the mini-max approach of Young (1998) to be special cases.

Young (1998) formulated an LP portfolio model for maximizing the minimum return to select a diversified portfolio based on historical returns data. He referred to the LP as a mini-max model because of its greater familiarity and this convention will be followed. The performance of the model was compared to other similar linear and nonlinear models and statistical analysis and simulation were employed to find that the mini-max approach outperformed the mean-variance approach with respect to mean square estimation error under the widely used log-normal distribution. He showed the mini-max modeling approach to be compatible with expected utility maximization and explored the incorporation of fixed transaction charges.

Cai at al. (2000) considered an objective of minimizing the expected absolute deviation of the future returns from their mean for several stocks and found that the problem could be solved analytically rather than solving a LP model. Similarly, Teo and Yang (2001) minimized the average of maximum individual risk over a number of time periods and the resulting optimization model was found to be solvable as a biobjective piecewise LP problem. Benati (2003) replaced the covariance objective of Markowitz $(1952,1959,1991,1997)$ with the worst conditional expectation resulting in a LP and developed an efficient algorithm for practical solutions to real-world sized problems. Ding (2006) considered LP models for maximizing the minimum returns but without the constraint for a minimum required average return for the portfolio as 
in Young (1998). For these simpler LP models he was able to develop optimal control policies for four cases of assumptions regarding evaluations (forecasts) for the potential returns. Gulpinar and Rustem (2007) proposed multiple alternative return and risk scenarios and developed a min-max algorithm to determine an optimal worst-case investment strategy.

Rockafellar and Uryasev (2000), Krokhmal et al. (2002), and Mansini et al. (2007) all focused upon minimizing conditional value-at-risk $(C V a R)$ and developed LP models, properties, and solution approaches for this setting. Schrage (2001) devoted a chapter to portfolio optimization featuring a LP model to maximize the minimum return and another to minimize expected downside risk. His wide-ranging treatment of this topic also included approximations for the covariance matrix, inclusion of transaction costs, and inclusion of taxes for the Markowitz $(1952,1959,1991,1997)$ model as well as the value-at-risk $(\mathrm{VaR})$ model and several deterministic equivalents of other stochastic optimization models. Alexander and Baptista $(2002,2004)$ incorporated $V a R$ and $C V a R$ as constraints in the Markowitz $(1952,1959,1991,1997)$ model and found the conditional value-at-risk approach dominant for managing risk. Benati and Rizzi (2007) formulated an integer linear programming model with valueat-risk replacing the covariance for the objective and developed properties for which polynomial time algorithms exist. Mansini et al. (2003a, b) provided a systematic overview, discussion of properties, and a computational comparison for LP solvable models for portfolio selection.

Kahneman and Tversky (1979) who thoroughly examine under-weighting and over-weighting of probabilities as key issues that may make insurance against losses attractive. Approaches for instance modeling began with Leland (1980) and Brennan and Solanki (1981) who examine maximizing expected utility subject to a budget constraint. But investor's preferences and probability belief may be difficult to ascertain and analyze so Aliprantis et al. (2000) introduced a LP approach to minimize the cost of a portfolio subject to a minimal payoff. Katsikis (2007) further refined computational approaches for this model. Aliprantis et al. (2002) extended the LP model by taking advantage of the situation where portfolio dominance information is also available.

Gilboa and Schmeidler (1989) employed a set of multiple prior probability distribution to model situation where the decision maker has too little information to discern a single prior distribution and expressed investor preferences as a utility function over this set. Chateauneuf et al. (2005) developed theoretical underpinnings for a number of important applications of the multiple priors. Gajdos et al. (2004) introduced a partial order on the set of multiple priors based on a reference prior distribution within the set termed an anchor. They proceeded to show that a decision maker who is averse to information imprecisions tends to maximize the minimum expected utility with respect to a subset of the multiple priors. Garlappi et al. (2007) employed confidence intervals around estimated expected returns to reflect decision making under multiple prior and modeled ambiguity aversion in terms of minimization of a function over these priors.

Sawik (2008) constructed the three stage lexicographic approach and the corresponding mixed integer programming formulations for the multi-criteria portfolio 
optimization problem. The primary objective is to maximize expected portfolio return, then the minimization of risk probability of portfolio loss versus the maximization of amount of capital to be invested in portfolio is considered, and finally the minimization of number of stocks in optimal portfolio is achieved. Some additional examples of the portfolio multi-criteria mixed integer programming formulations with use of the VaR can be found in Sawik (2009a, 2009b, 2010).

Polak et al. (2010) constructed mini-max portfolio model with linear programming approach. Employed risk measured as the worst-case return and a portfolio from maximizing returns subject to a risk threshold. They proceeded to show parametric analysis of the risk threshold connected their model to expected value along a continuum, revealing an efficient frontier segmenting investors by risk preferences.

Chen and Kwon (2010) develop a robust portfolio selection model for tracking a market index using a subset of its assets. The model is a binary program that seeks to maximize similarity between selected assets and the assets of the target index. Presented optimization model allows uncertainty in the objective function by using a computationally tractable robust framework that can control the conservativeness of the solution. This protects against worst-case realizations of potential estimation errors and other deviations.

\section{PERCENTILE MEASURES OF RISK IN THE LITERATURE}

In the mean-variance context of Markowitz $(1952,1959,1991,1997)$, the variance or standard deviation is adopted to measure the risk exposure of financial portfolios (see e.g. Bai et al., 2009a, 2009b; Leung and Wong, 2008). However, these measures fail to capture the downside risk. To circumvent this problem, many academics have proposed value-at-risk $(\mathrm{VaR})$ (Jourion, 2006) and the conditional value-at-risk $(C V a R)$ (Alexander and Baptista, 2002, 2004; Sarykalin et al., 2008).

Generally risk management has received much attention from practitioners and regulators as well as academics in the last few years, with value-at-risk emerging as one of the most popular tools. Jourion (2006), Linsmeier and Pearson (2000), Alexander and Baptista (2002, 2004), Hull (2003), and Chance (2004) note that valueat-risk is widely used as a risk management tool by corporate treasurers, dealers, fund managers, financial institutions, and regulators (see Basel Committee on Banking Supervision (1996, 2003)).

In contrast, some researchers have extensively criticized the use of value-at-risk as a measure of risk. For instance Artzner et al. (1999) pointed out that value-at-risk is not a coherent measure of risk since it fails to hold the sub-additivity property. Moreover, value-at-risk does not explain the magnitude of the loss when the value-atrisk limit is exceeded. Furthermore, it is difficult to optimize when using calculated scenarios, and this leads to the use of an alternative measure, which is conditional value-at-risk.

Basak and Shapiro (2001) show that when an agent faces a value-at-risk constraint at the initial date in a continuous-time model, the agent may select a larger exposure to risky securities than he or she would have chosen in its absence. Yiu (2004) shows that imposing a dynamic constraint in a continuous-time model leads 
an agent to select a smaller exposure to risky stocks than it would have been chosen in case of its absence. This reasons incline mentioned previously researchers to proposed use of conditional value-at-risk rather than value-at-risk. Pflug (2000) proved that conditional value-at-risk is a consistent measure of risk for its sub-additivity and convexity properties. Uryasev (2000) presented a description of both: (a) an approach for minimizing conditional value-at-risk and (b) optimization problems with conditional value-at-risk constraints. Alexander and Baptista (2004) noticed that the presence of a value-at-risk constraint will cause a slightly risk-averse agent to select a portfolio that has a smaller standard deviation than the one that would have been selected in its absence. However, there are also conditions under which the constraint causes a highly risk-averse agent to select a portfolio that has a larger standard deviation. Conditional value-at-risk constraint is tighter than a value-at-risk constraint when the conditional value-at-risk and value-at-risk bounds coincide, these portfolio choice results are also true and to a greater extent if a conditional value-at-risk constraint is imposed. Therefore, a conditional value-at-risk constraint is more effective than a value-at-risk constraint as a tool to control slightly risk-averse agents, but has a more perverse effect on highly risk-averse agents.

However, this perverse result weakens or even disappears when a risk-free security is available, or the conditional value-at-risk bound is larger than the value-at-risk bound. Moreover, if the conditional value-at-risk bound is set at a level so that conditional value-at-risk constraint has the same perverse effect on highly risk-averse agents as the value-at-risk constraints, then the conditional value-at-risk constraint will result in slightly risk-averse agents selecting portfolios with small standard deviations than those when a value-at-risk constraint is imposed. If the conditional value-at-risk bound is set at an even larger level so that the conditional value-at-risk constraint decreases the standard deviations of the optimal portfolios of slightly risk-averse agents to select portfolios with smaller standard deviations than those when a value-at-risk constraint is imposed. Hence, when the conditional value-at-risk bound is set between these two levels, a conditional value-at-risk constraint dominates a value-at-risk constraints as a risk management tool.

The proposed multi-criteria portfolio approach allows aforementioned two percentile measures of risk in financial engineering: value-at-risk and conditional value-atrisk to be applied for managing the risk of portfolio loss. The proposed mixed integer and linear programming models provide the decision maker with a simple tool for evaluating the relationship between expected and worst-case loss of portfolio return. A risk measure can be linear program computable in the case of discrete random variables, i.e., in the case of returns defined by their realizations under specified scenarios. $V a R$ and $C V a R$ have been widely used in financial engineering in the field of portfolio management (e.g. Sarykalin et al. (2008)). $C V a R$ is used in conjunction with $V a R$ and is applied for estimating the risk with non-symmetric cost distributions. Uryasev (2000) and Rockafellar and Uryasev $(2000,2002)$ introduced a new approach to select a portfolio with the reduced risk of high losses. The portfolio is optimized by calculating $V a R$ and minimizing $C V a R$ simultaneously. Polak et al. (2010) noticed that objectives such as minimizing variation or the popular value-at-risk objective may be quite effective especially during periods of slow or moderate economic changes. 


\section{DEFINITIONS OF PERCENTILE MEASURES OF RISK}

Let $\alpha \in(0,1)$ be the confidence level.

The percentile measures of risk, $V a R$ and $C V a R$ can be defined as below:

- Value-at-Risk $(\mathrm{VaR})$ at a $100 \alpha \%$ confidence level is the targeted return of the portfolio such that for $100 \alpha \%$ of outcomess the return will not exceed $V a R$. In other words, $V a R$ is a decision variable based on the $\alpha$-percentile of return, i.e., in $100(1-\alpha) \%$ of outcomes the return may not attain $V a R$.

- Conditional Value-at-Risk $(C V a R)$ at a $100 \alpha \%$ confidence level is the expected return of the portfolio in the worst $100(1-\alpha) \%$ of the cases. Allowing $100(1-$ $\alpha) \%$ of the outcomes not exceed $V a R$, and the mean value of these outcomes is represented by $C V a R$.

Figure 1 illustrates value-at-risk and conditional value-at-risk for a given portfolio and the confidence level $\alpha$.

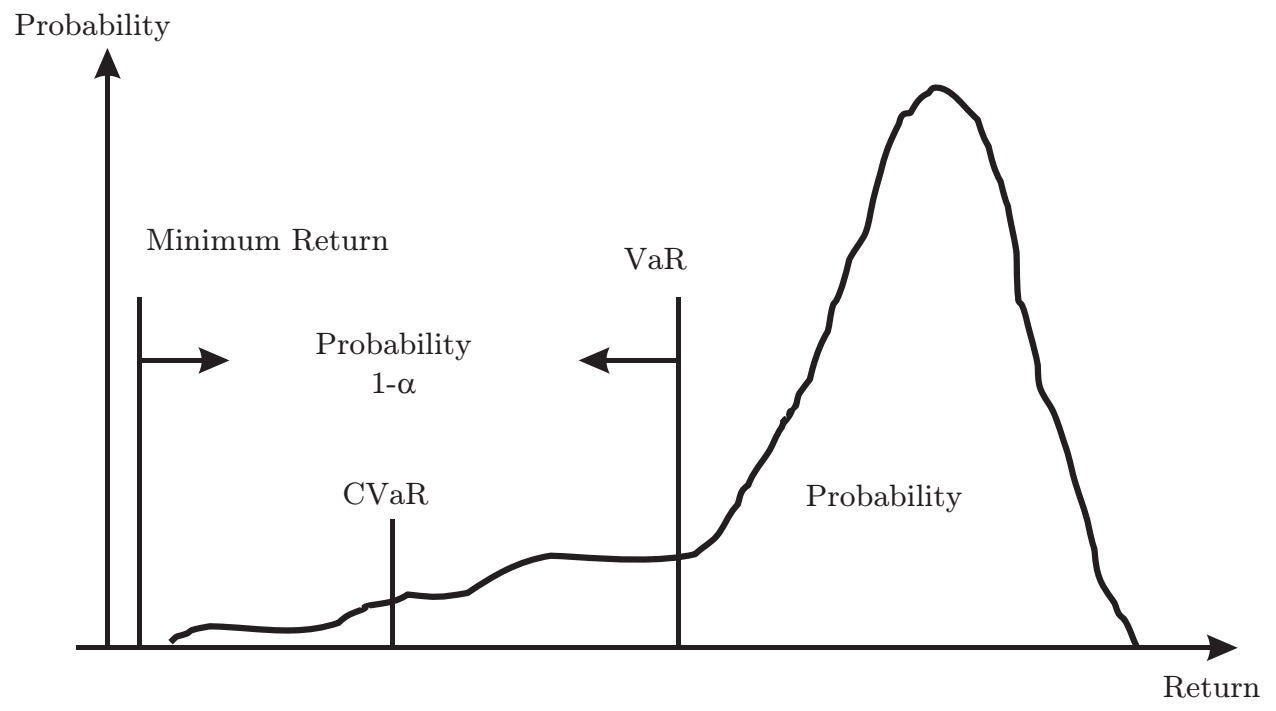

Fig. 1. Value-at-Risk and Conditional Value-at-Risk

Value-at-risk represents the minimum return associated with a specified confidence level of outcomes (i.e., the likelihood that a given portfolio's return will not be less than the amount defined as $V a R$ ). However, $V a R$ does not account for properties of the cost distribution beyond the confidence level and hence does not explain the magnitude of the return when the $V a R$ limit is not exceeded. On the other hand, $C V a R$ (conditional value-at-risk) focuses on the tail of the return distribution, that is, on outcomes with the lowest return.

Since $V a R$ and $C V a R$ measure different parts of the cost distribution, $V a R$ may be better for optimizing portfolios when good models for tails are not available, otherwise $C V a R$ may be preferred, e.g. (Rockafellar, 2000, 2002; Sarykalin, 2008; Uryasev, 2000). When using $C V a R$ to minimize worst-case costs, $C V a R$ is always less than $V a R$. 


\section{PROBLEM FORMULATION}

This section presents mathematical programming formulations $\mathbf{C V}$ and $\mathbf{E} \_\mathbf{C V}$, respectively for the single- and bi-objective selection of optimal portfolio. Table 1 shows the notation used in this section.

Table 1. Notation

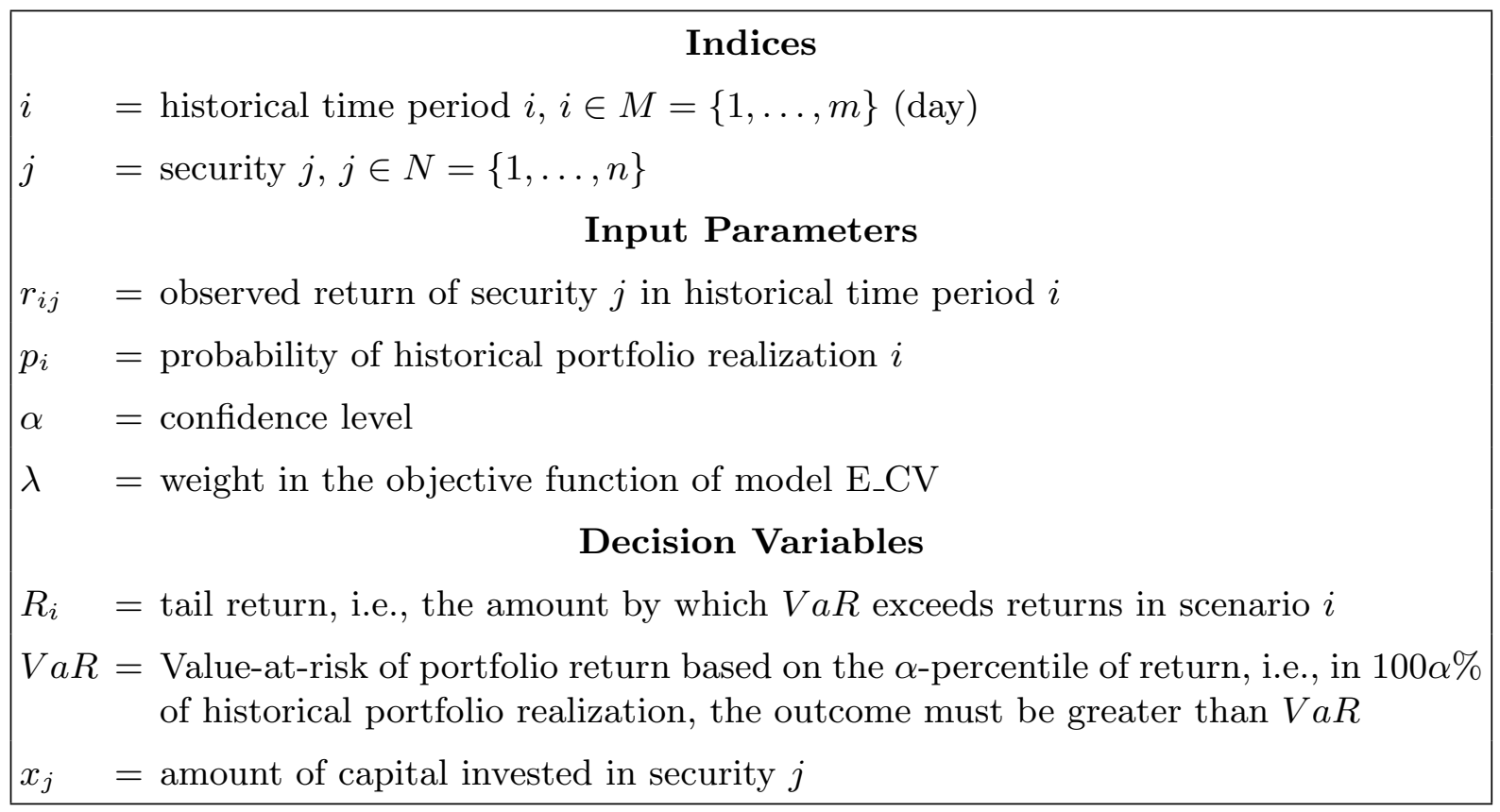

In the risk averse objective (1), VaR is a decision variable denoting the Valueat-risk. Let $\alpha$ be the confidence level for the total portfolio return distribution across all historical portfolios. It can also be said that $V a R$ is a decision variable based on the $\alpha$-percentile of portfolio return, for instance, in $100(1-\alpha) \%$ of the historical portfolios, the outcome will not exceed $V a R$.

Finally, $C V a R$ is a weighted measure of $V a R$ and the portfolio return below $\operatorname{VaR}$ (which, again, could be an extremely small return or actually losses). $R_{i}$ is defined as the tail portfolio return for scenario (historic portfolio) $i$, i.e., the amount by which $V a R$ exceeds the average return in portfolio $i$.

\section{Model CV}

Maximize

$$
V a R-(1-\alpha)^{-1} \sum_{i \in M} p_{i} R_{i}
$$

subject to

$$
\sum_{j \in N} x_{j}=1
$$




$$
\begin{gathered}
R_{i} \geqslant V a R-\sum_{j \in N} r_{i j} x_{j} ; i \in M \\
x_{j}=0 ; j \in N: \sum_{i \in M} p_{i} r_{i j} \leqslant 0 \\
x_{j} \geqslant 0 ; j \in N \\
R_{i} \geqslant 0 ; i \in M
\end{gathered}
$$

Constraint (2) ensures that all capital is invested in the portfolio (the selected securities). Risk constraint (3) defines the tail losses for scenario $i$. Constraint (4) eliminates from selection the assets with non-positive expected return over all scenarios. Eq. (5) and (6) are non-negativity conditions.

A risk-aversive decision maker wants to maximize the Conditional Value-at-Risk, as shown in the objective functions of models $\mathbf{C V}$ and $\mathbf{E} \_\mathbf{C V}$. Note that as $R_{i}$ is constrained of being positive, the models tries to increase $V a R$ and hence positively impact the objective functions. However, large increases in $V a R$ may result in more historic portfolios (scenarios) with tail returns, counterbalancing this effect.

The portfolio model E_CV presented below provides flexibility in how a decision maker wants to balance its risk tolerance with the expected portfolio returns.

\section{Model E_CV}

Maximize

$$
\lambda\left(\operatorname{VaR}-(1-\alpha)^{-1} \sum_{i \in M} p_{i} R_{i}\right)+(1-\lambda)\left(\sum_{i \in M} p_{i}\left(\sum_{j \in N} r_{i j} x_{j}\right)\right.
$$

subject to $(2),(3),(4),(5),(6)$.

The nondominated solution set of the bi-criterion portfolio can be found by the parametrization on $\lambda$ the weighted-sum program E_CV.

\section{COMPUTATIONAL EXAMPLES}

In this section the strength of $C V a R$ approach and LP models $\mathbf{C V}$ and $\mathbf{E} \_\mathbf{C V}$ is demonstrated on computational examples. The data sets for the example problems were based on historic daily portfolios of the Warsaw Stock Exchange ranging from 1000 days (from 29th of July 2005 to 30th of January 2009) and 135 securities, through 3500 days (from 30th April 1991 to 31st of January 2007) and 250 securities, to 4020 days (from 30th April 1991 to 30th of January 2009) and 240 securities.

In the computational experiments the five levels of the confidence level was applied $\alpha \in\{0.99,0.95,0.90,0.75,0.50\}$, and for the weighted sum program E_CV the subset of nondominated solutions were computed by parametrization on $\lambda \in\{0,0.1,0.2,0.3,0.4,0.5,0.6,0.7,0.8,0.9,1\}$. 
The results obtained for model $\mathbf{C V}$ are presented in Table 2 and in Figures 2 and 3. Table 2 shows the optimal values of $C V a R, V a R$, and the expected portfolio return for different confidence level $\alpha$ and the size of the input data set. In all cases the CPU time increases when the confidence level decreases. The number of securities in the optimal portfolios varies between 14 and 39 assets. The relation between the conditional value-at-risk $C V a R$ and the confidence level $\alpha$ is also shown in Figure 2 . $V a R$ and $C V a R$ increase as the confidence level decreases.

Figure 3 shows the number of securities in the computed portfolio and the computational time range for different size of input data set and model $\mathbf{C V}$. The number of stocks selected for the optimal portfolio is independent on the confidence level and the size of input data set. The computational results for model E_CV are presented in Figures 4-9 and Table 3. The conditional value-at-risk is more negative than value-at-risk, which is clearly shown in Figures 4 and 5.
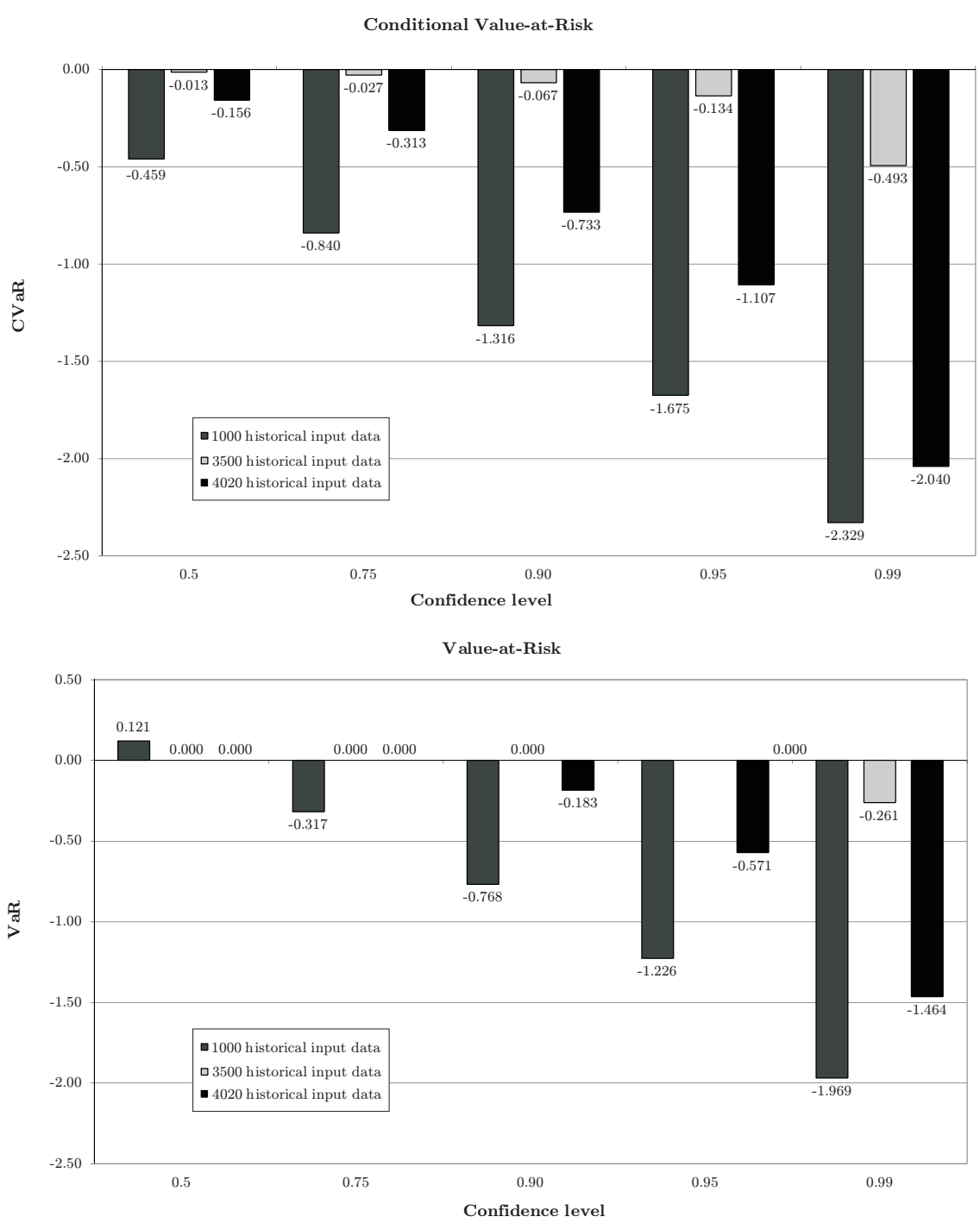

Fig. 2. Comparison of $C V a R, V a R$ and the expected return for $\mathbf{C V}$ model with 1000, 3500 and 4020 historical input data 


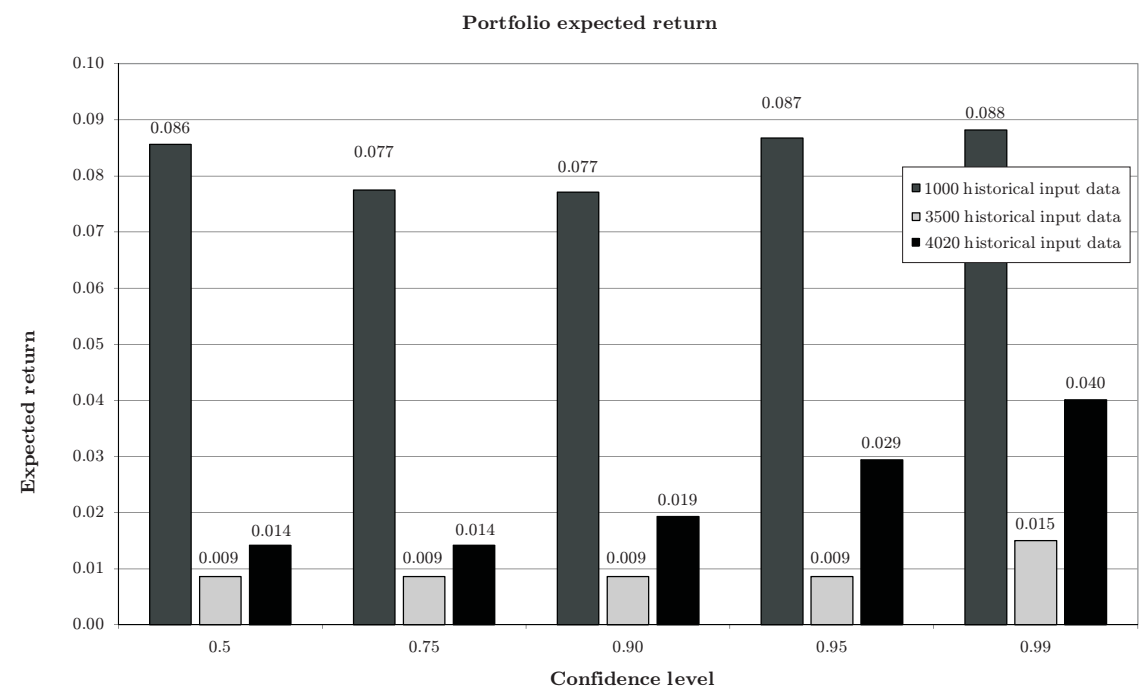

Fig. 2. (continued)

Table 2. Solutions results for $\mathbf{C V}$ model and 1000, 3500 and 4020 historical input data

\begin{tabular}{|c|c|c|c|c|c|}
\hline Confidence level $\alpha$ & 0.99 & 0.95 & 0.90 & 0.75 & 0.50 \\
\hline \multicolumn{6}{|c|}{1000 input data, Var. $=1136$, Cons. $=1001$, Nonz. $=118100$} \\
\hline CVaR & -2.329320 & -1.674800 & -1.316210 & -0.839905 & -0.458828 \\
\hline VaR & -1.968690 & -1.225590 & -0.767942 & -0.316816 & 0.120616 \\
\hline Expected portfolio return & 0.088178 & 0.086781 & 0.077124 & 0.077459 & 0.085606 \\
\hline No. of securities in portfolio & 16 & 25 & 30 & 30 & 39 \\
\hline Dual simplex iterations & 226 & 506 & 948 & 1716 & 2202 \\
\hline $\mathrm{CPU}(a)$ & 0.124 & 0.202 & 0.358 & 0.686 & 0.951 \\
\hline$(1-\alpha)^{-1} \sum_{i=1}^{m} p_{i} R_{i}$ & 0.360628 & 0.449209 & 0.548270 & 0.523088 & 0.579444 \\
\hline No. of non-zero $R_{i}$ & 4 & 38 & 86 & 270 & 478 \\
\hline Confidence level $\alpha$ & 0.99 & 0.95 & 0.90 & 0.75 & 0.50 \\
\hline \multicolumn{6}{|c|}{3500 input data, Var. $=3736$, Cons. $=3501$, Nonz. $=332550$} \\
\hline CVaR & -0.492633 & -0.133975 & -0.066987 & -0.026795 & -0.013398 \\
\hline VaR & -0.260505 & 0.000000 & 0.000000 & 0.000000 & 0.000000 \\
\hline Expected portfolio return & 0.014985 & 0.008625 & 0.008625 & 0.008625 & 0.008625 \\
\hline No. of securities in portfolio & 37 & 14 & 14 & 14 & 14 \\
\hline Dual simplex iterations & 883 & 2065 & 2062 & 2800 & 4871 \\
\hline $\mathrm{CPU}^{(a)}$ & 1.029 & 2.854 & 3.385 & 4.336 & 8.127 \\
\hline$(1-\alpha)^{-1} \sum_{i=1}^{m} p_{i} R_{i}$ & 0.232127 & 0.133975 & 0.066987 & 0.026795 & 0.013397 \\
\hline No. of non-zero $R_{i}$ & 20 & 56 & 56 & 56 & 56 \\
\hline Confidence level $\alpha$ & 0.99 & 0.95 & 0.90 & 0.75 & 0.50 \\
\hline \multicolumn{6}{|c|}{4020 input data, Var. $=4189$, Cons. $=4021$, Nonz. $=349555$} \\
\hline CVaR & -2.039670 & -1.106810 & -0.733006 & -0.312627 & -0.156314 \\
\hline VaR & -1.464350 & -0.570700 & -0.183289 & 0.000000 & 0.000000 \\
\hline Expected portfolio return & 0.040122 & 0.029419 & 0.019309 & 0.014214 & 0.014214 \\
\hline No. of securities in portfolio & 23 & 34 & 39 & 27 & 27 \\
\hline Dual simplex iterations & 582 & 2217 & 3414 & 6058 & 8019 \\
\hline $\mathrm{CPU}^{(a)}$ & 0.702 & 2.730 & 3.993 & 9.048 & 12.854 \\
\hline$(1-\alpha)^{-1} \sum_{i=1}^{m} p_{i} R_{i}$ & 0.575319 & 0.536106 & 0.549717 & 0.312627 & 0.156314 \\
\hline No. of non-zero $R_{i}$ & 30 & 184 & 384 & 557 & 557 \\
\hline
\end{tabular}

(a) CPU seconds for proving optimality on a laptop with Intel $\AA$ Core 2 Duo T9300, 2.5GHz, RAM 4GB, CPLEX v.11. 

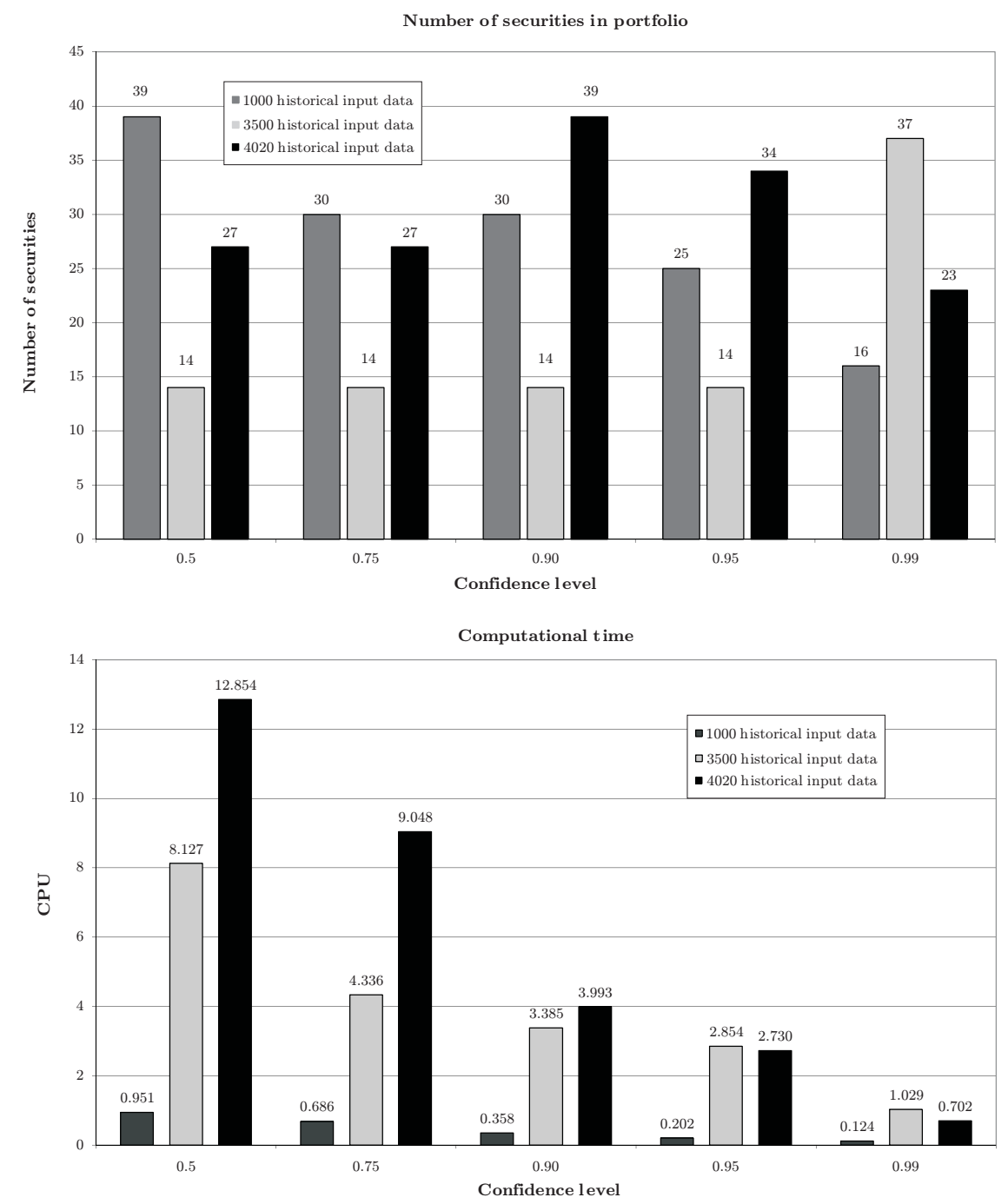

Fig. 3. Number of securities in an optimal portfolio and computational time range for $\mathbf{C V}$ model with 1000, 3500 and 4020 input data

The confidence level $\alpha$ has a strong impact on obtained values $C V a R$ and $V a R$. The expected portfolio returns for different confidence level alpha and weight $\lambda$ and for the three different historical portfolios are shown in Figure 6. Figure 7 shows that the number of securities selected for the optimal portfolio does not clearly depend either on the confidence level $\alpha$, or on the size of the historical input data set. In weighted-sum program the weight $\lambda$ only slightly influences the number of selected stock.

Figure 8 presents the efficient frontiers of the bi-objective model $\mathbf{E} \_\mathbf{C V}$ - conditional value-at-risk vs. expected return for the three different historical scenarios. The trade-off between the conditional value-at-risk and expected portfolio return is clearly shown as a concave efficient frontier. Figure 9 presents the CPU time required to obtain the optimal solution for $\mathbf{E} \_\mathbf{C V}$ model for different historical input data set. The computational time increases with the confidence level $\alpha$ and the size of input data set. 


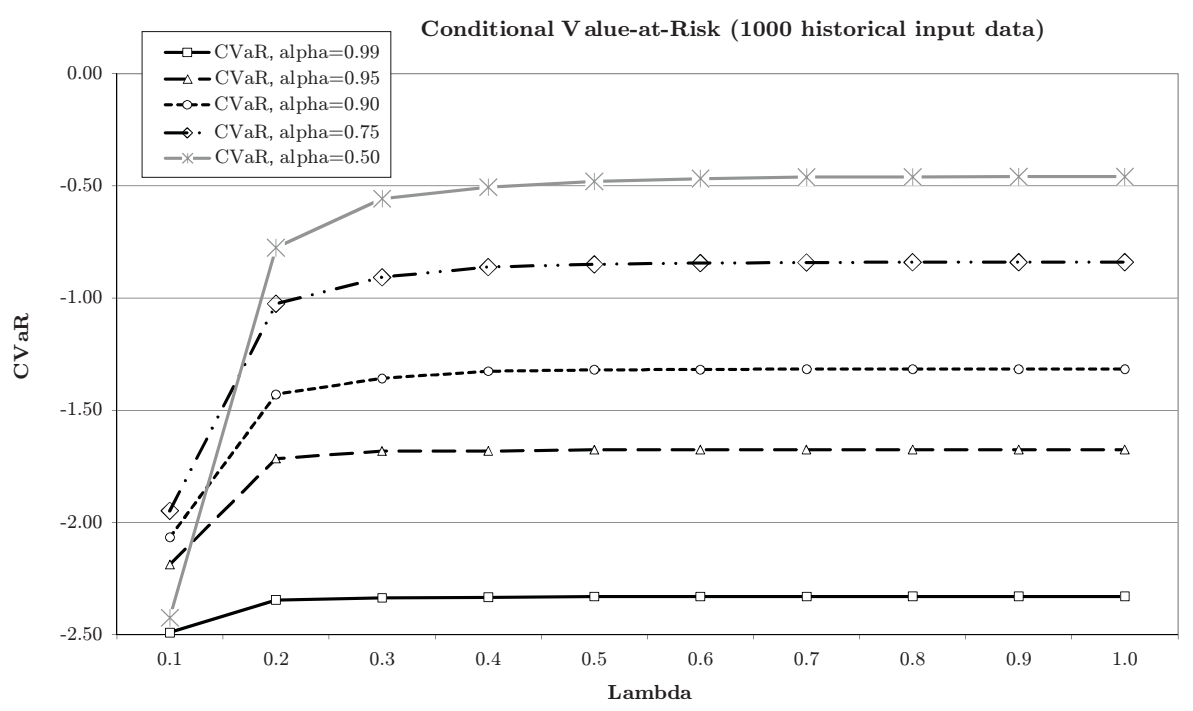

Conditional V alue-at-Risk (3500 historical input data)

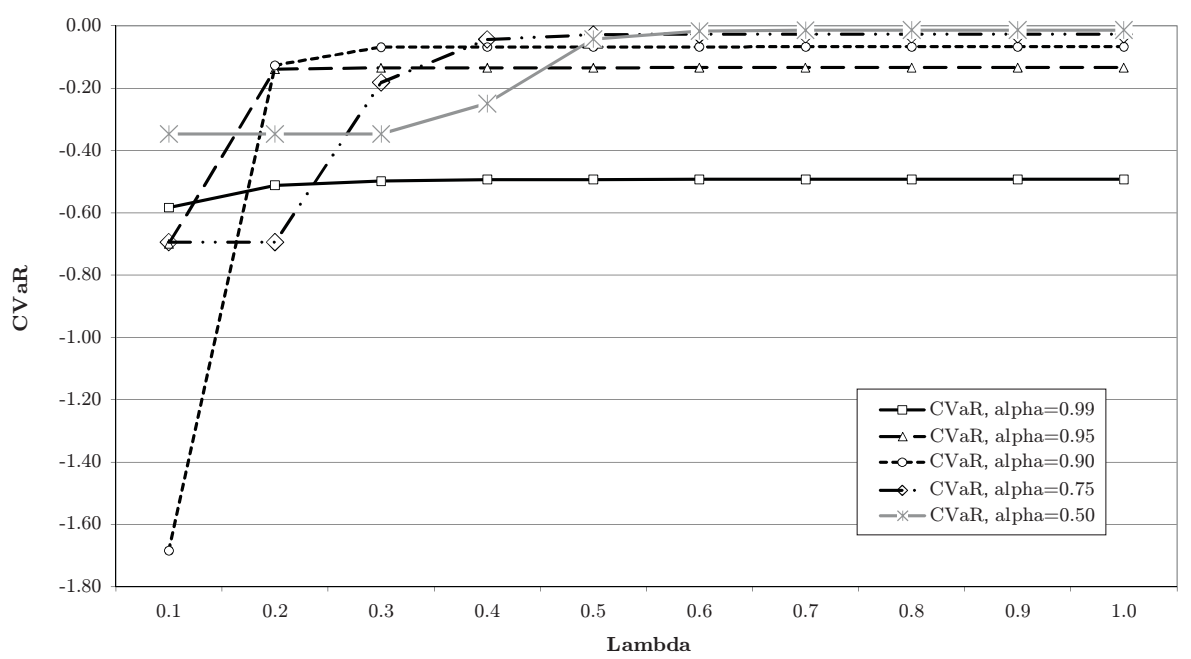

Conditional V alue-at-Risk (4200 historical input data)

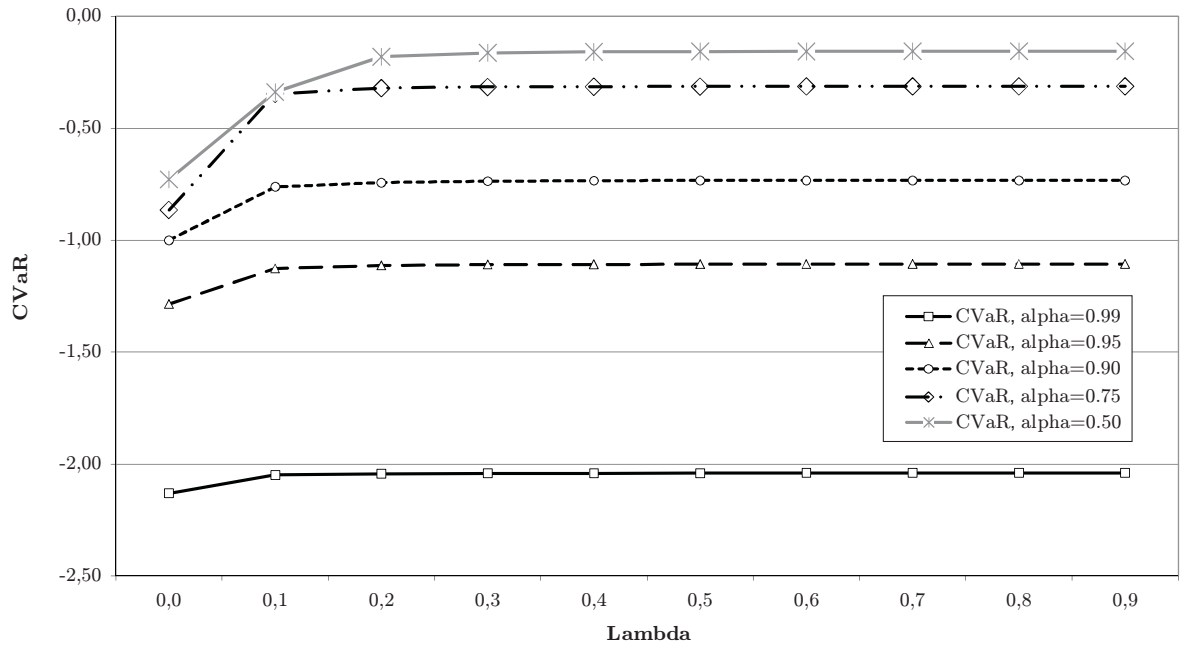

Fig. 4. Conditional Value-at-Risk for different confidence levels, and 1000, 3500 and 4020 historical input data - model E_CV 

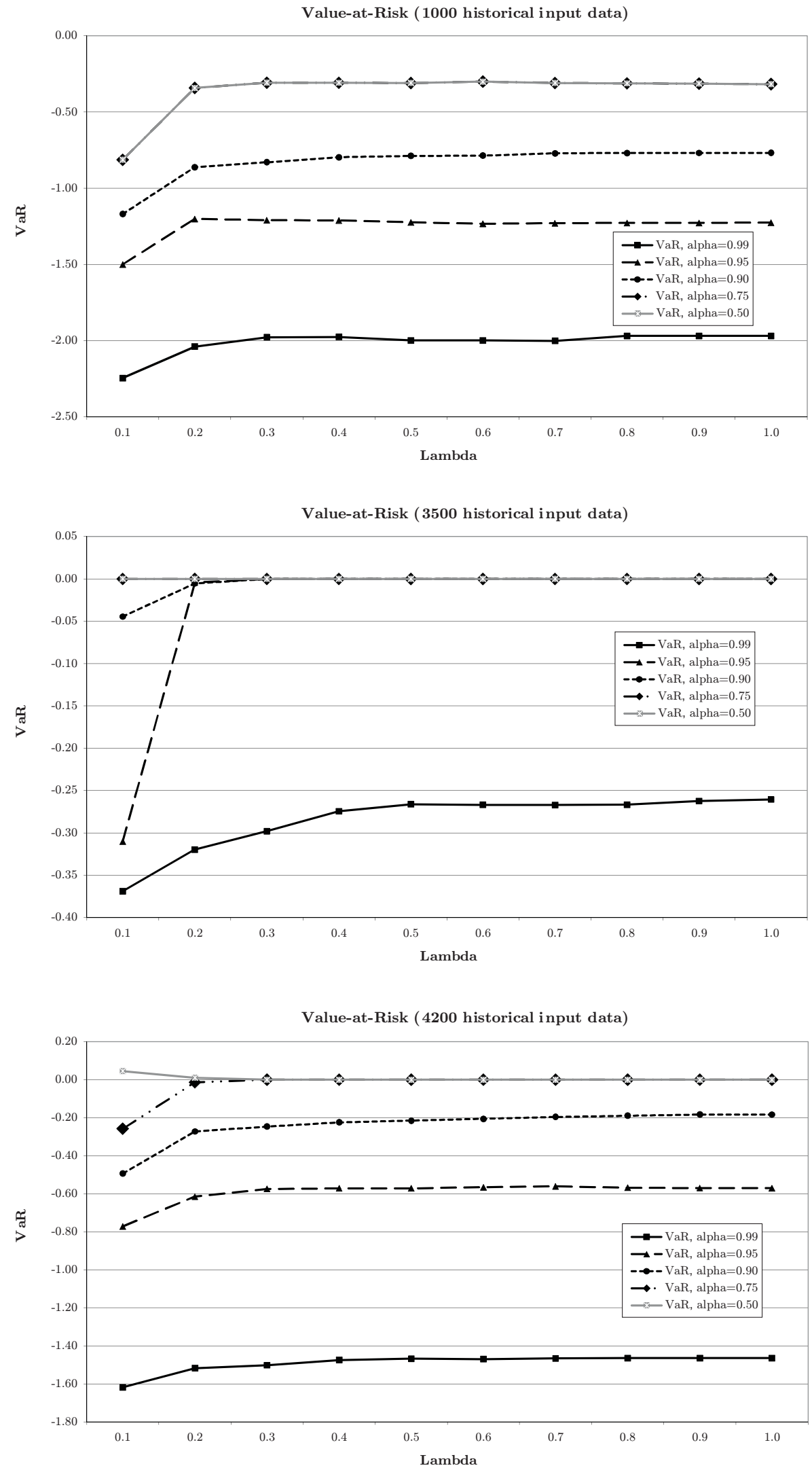

Fig. 5. Value-at-Risk for different confidence levels and 1000, 3500 and 4020 historical input data - model E_CV 
Expected portfolio return (1000 historical input data)
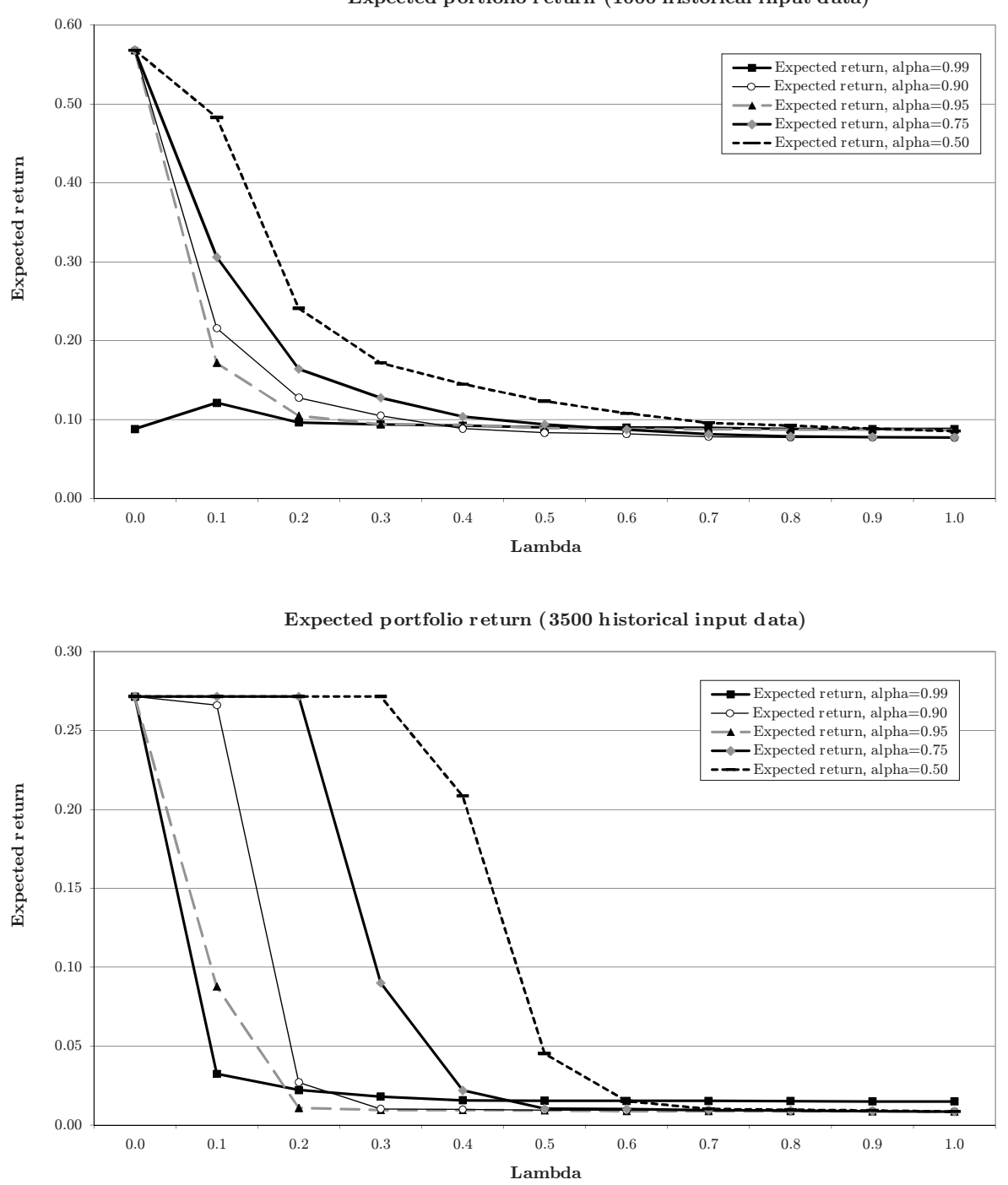

Expected portfolio return (4020 historical input data)

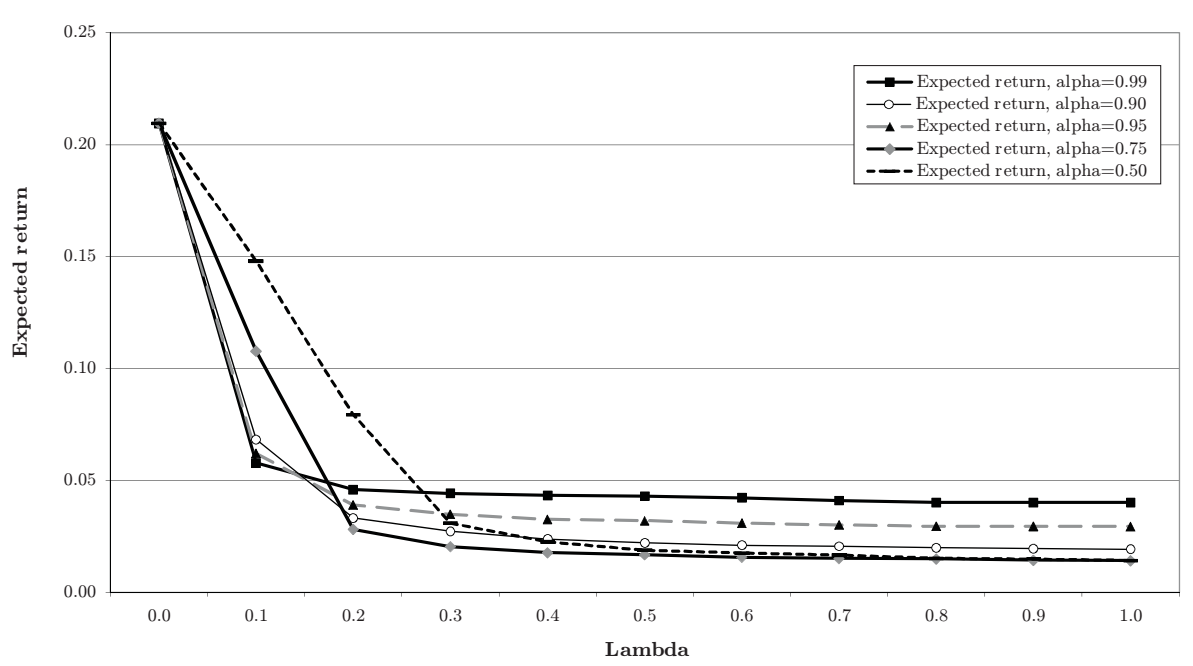

Fig. 6. Expected portfolio return for different confidence levels and 1000, 3500, 4020 historical input data - model $\mathbf{E} \_\mathbf{C V}$ 


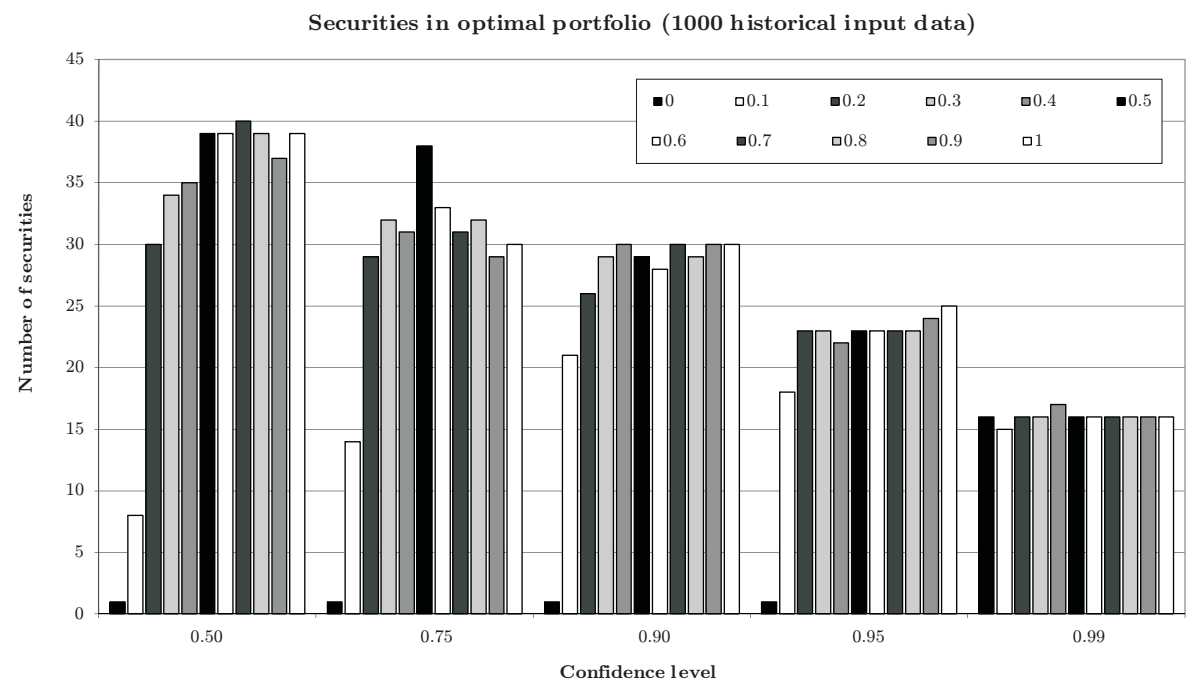

Securities in optimal portfolio ( $3500 \mathrm{~h}$ istorical input data)

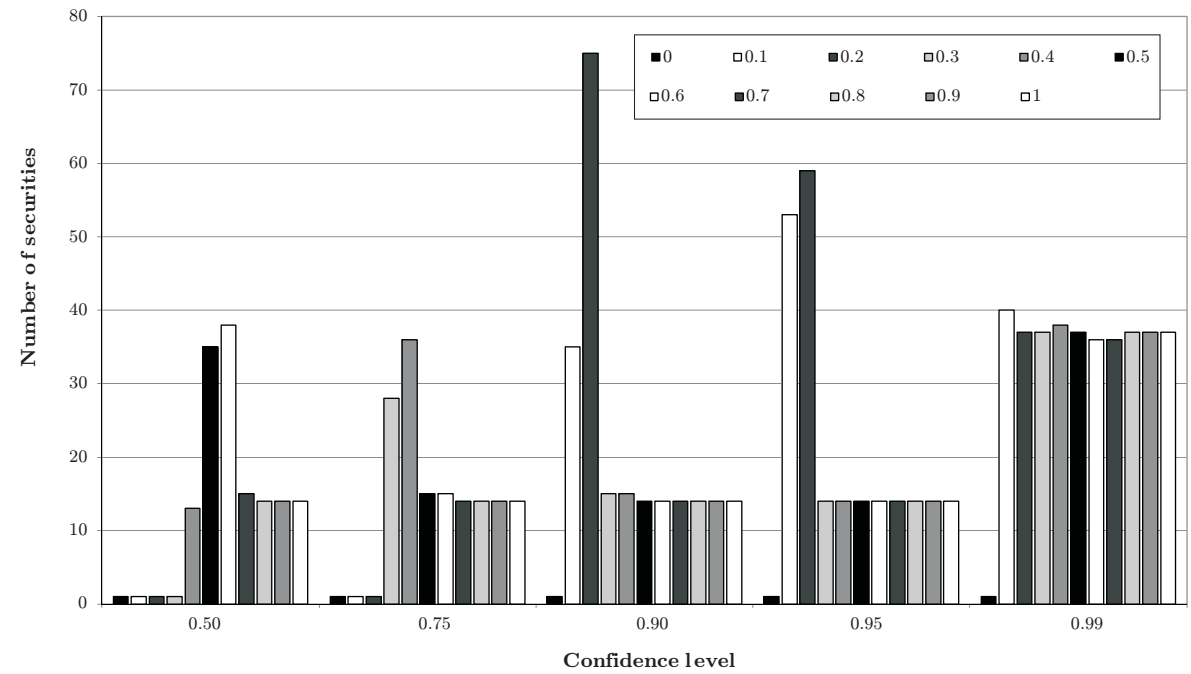

Securities in optimal portfolio (4020 historical input data)

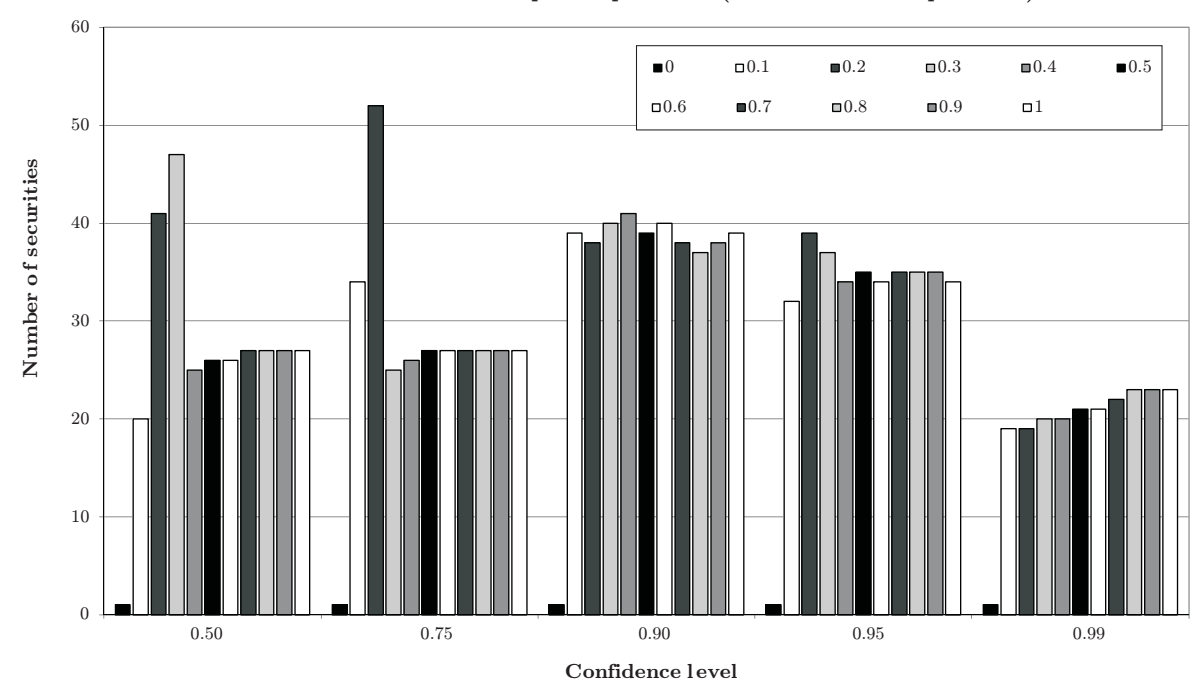

Fig. 7. Number of assets in the optimal portfolio for 1000, 3500, 4020 historical input data - model E_CV 

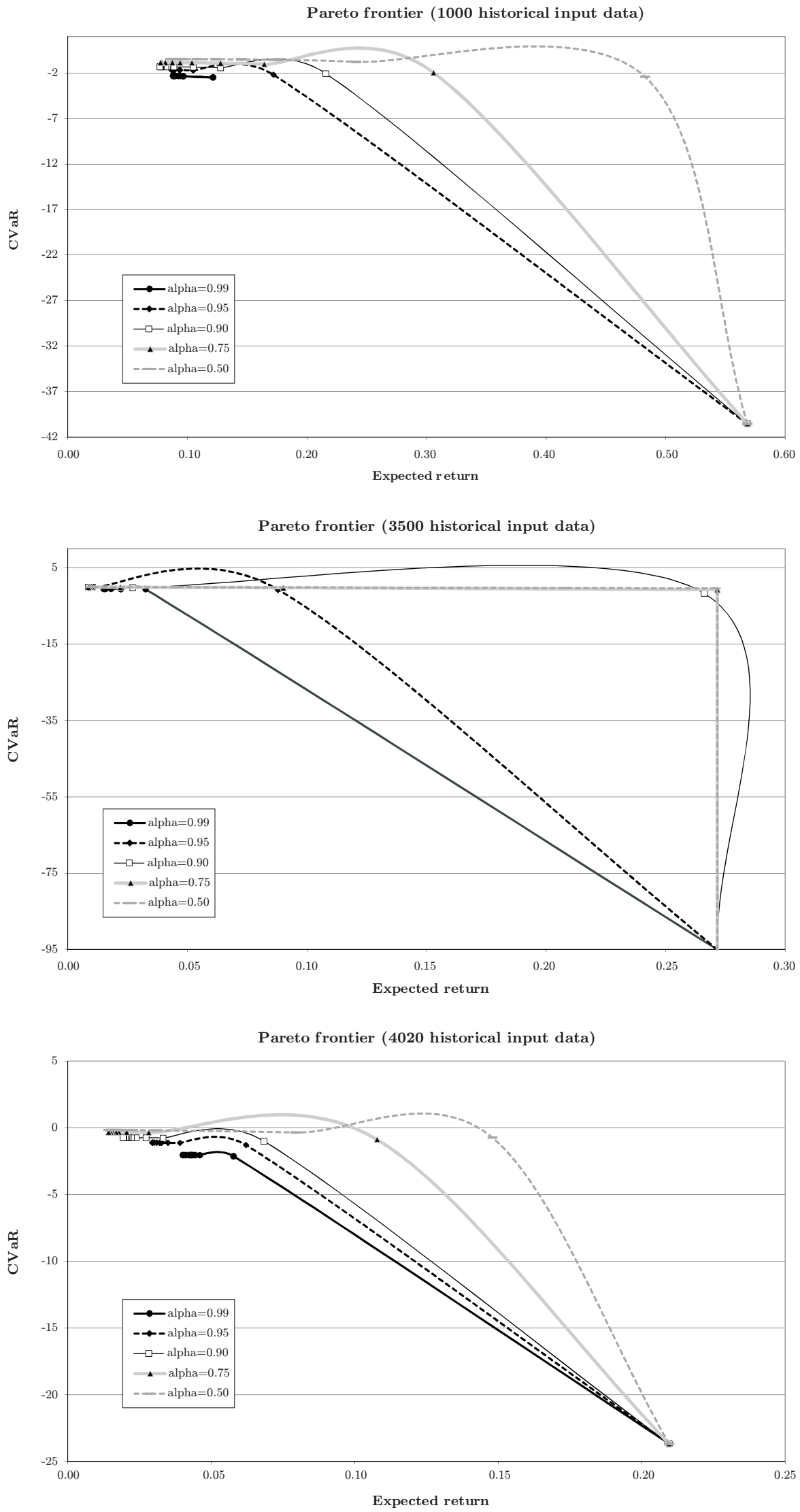

Fig. 8. Pareto frontier for the bi-objective model $\mathbf{E} \_\mathbf{C V}$ for the three different scenario sizes 
Computational time (1000 historical input data)
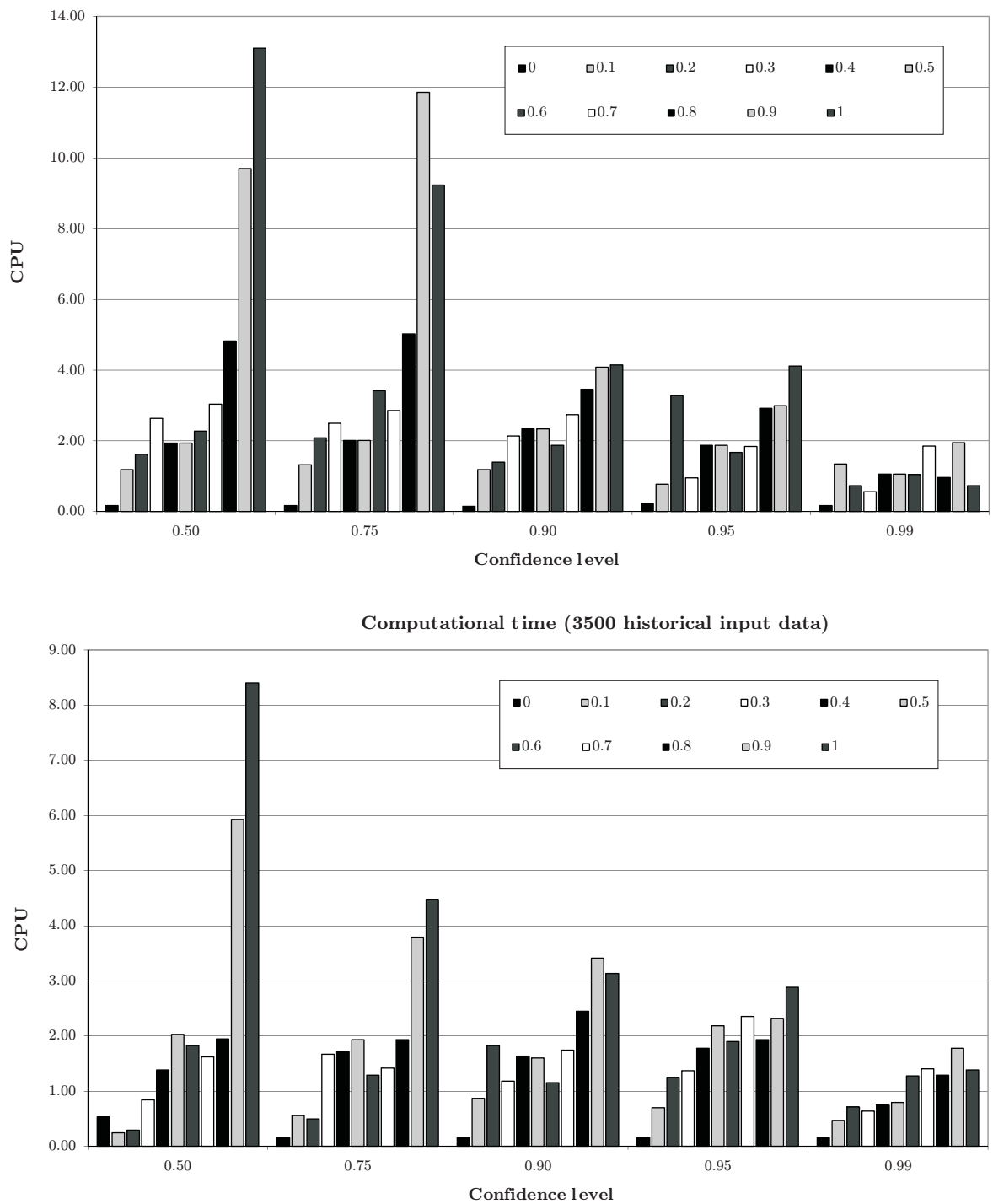

Computational time (4020 historical input data)

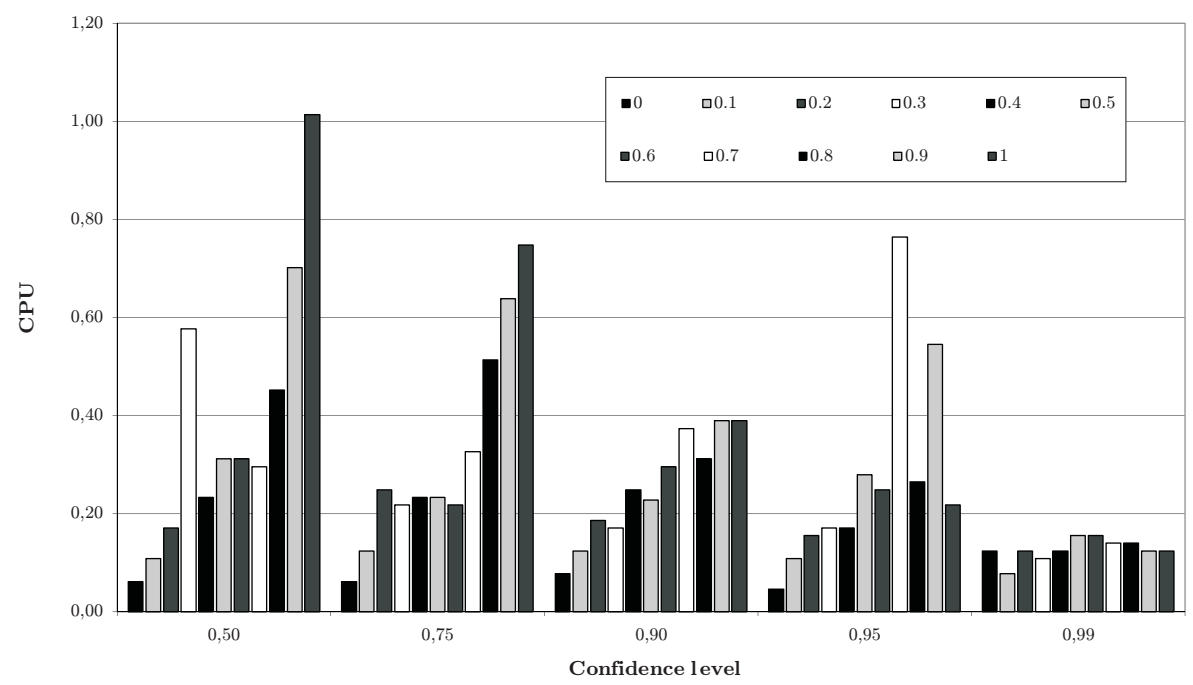

Fig. 9. Central processing unit - computational time for model $\mathbf{E}+\mathbf{C V}$ and the three different historical scenarios 
The examples of nondominated solutions for model $\mathbf{E} \_\mathbf{C V}$ with different values of the confidence level alpha and for 4020 historic portfolios (scenarios) are presented in Table 3.

Table 3. Nondominated solutions for the weighted-sum program $\mathbf{E} \_\mathbf{C V}$ for different confidence levels $\alpha$ and for 4020 historical input data

\begin{tabular}{|c|c|c|c|c|c|c|c|c|c|c|c|}
\hline$\lambda$ & 0.0 & 0.1 & 0.2 & 0.3 & 0.4 & 0.5 & 0.6 & 0.7 & 0.8 & 0.9 & 1.0 \\
\hline \multicolumn{12}{|c|}{$\alpha=0.99$} \\
\hline \multicolumn{12}{|c|}{ Var. $=4189$, Cons. $=4021$, Nonz. $=349555$} \\
\hline CVaR & $\mid-23.6607$ & -2.1309 & -2.0491 & -2.0437 & -2.0420 & -2.0414 & -2.0408 & -2.0401 & -2.0397 & -2.0397 & -2.0397 \\
\hline VaR & -23.6607 & -1.6186 & -1.5172 & -1.5021 & -1.4748 & -1.4680 & -1.4699 & -1.4664 & -1.4644 & -1.4644 & -1.4644 \\
\hline Expected return & 0.2096 & 0.0578 & 0.0459 & 0.0443 & 0.0434 & 0.0430 & 0.0423 & 0.0410 & 0.0401 & 0.0401 & 0.0401 \\
\hline No. of assets & 1 & 19 & 19 & 20 & 20 & 21 & 21 & 22 & 23 & 23 & 23 \\
\hline Dual simplex iter. & 0 & 412 & 609 & 518 & 640 & 730 & 636 & 668 & 693 & 739 & 582 \\
\hline $\mathrm{CPU}$ & 0.173 & 1.341 & 0.733 & 0.561 & 0.748 & 1.060 & 1.045 & 1.856 & 0.967 & 1.950 & 0.733 \\
\hline$(1-\alpha)^{-1} \sum_{i=1}^{m} p_{i} R_{i}$ & 0.0000 & 0.5123 & 0.5320 & 0.5416 & 0.5672 & 0.5735 & 0.5709 & 0.5737 & 0.5753 & 0.5753 & 0.5753 \\
\hline No. of non-zero $R_{i}$ & 0 & 30 & 30 & 30 & 31 & 31 & 29 & 30 & 30 & 30 & 30 \\
\hline \multicolumn{12}{|c|}{$\alpha=0.95$} \\
\hline \multicolumn{12}{|c|}{ Var. $=4189$, Cons. $=4021$, Nonz. $=349555$} \\
\hline CVaR & $\mid-23.6607$ & -1.2846 & -1.1268 & -1.1134 & -1.1091 & -1.1084 & -1.1075 & -1.1070 & -1.1068 & -1.1068 & -1.1068 \\
\hline VaR & -23.6607 & -0.7719 & -0.6147 & -0.5743 & -0.5708 & -0.5712 & -0.5660 & -0.5611 & -0.5677 & -0.5692 & -0.5707 \\
\hline Expected return & 0.2096 & 0.0621 & 0.0390 & 0.0349 & 0.0326 & 0.0320 & 0.0310 & 0.0301 & 0.0295 & 0.0295 & 0.0294 \\
\hline No. of assets & 1 & 32 & 39 & 37 & 34 & 35 & 34 & 35 & 35 & 35 & 34 \\
\hline Dual simplex iter. & 0 & 1232 & 1426 & 1388 & 1745 & 1797 & 1784 & 1780 & 2148 & 2013 & 2217 \\
\hline $\mathrm{CPU}$ & 0.234 & 0.780 & 3.276 & 0.951 & 1.872 & 1.872 & 1.669 & 1.840 & 2.917 & 2.995 & 4.118 \\
\hline$(1-\alpha)^{-1} \sum_{i=1}^{m} p_{i} R_{i}$ & 0.0000 & 0.5127 & 0.5121 & 0.5391 & 0.5383 & 0.5372 & 0.5415 & 0.5459 & 0.5391 & 0.5376 & 0.5361 \\
\hline No. of non-zero $R_{i}$ & 0 & 183 & 182 & 184 & 185 & 185 & 186 & 182 & 185 & 186 & 180 \\
\hline \multicolumn{12}{|c|}{$\alpha=0.90$} \\
\hline \multicolumn{12}{|c|}{ Var. $=4189$, Cons. $=4021$, Nonz. $=349555$} \\
\hline CVaR & -23.6607 & -1.0003 & -0.7620 & -0.7430 & -0.7365 & -0.7344 & -0.7336 & -0.7333 & -0.7331 & -0.7330 & -0.7330 \\
\hline VaR & -23.6607 & -0.4936 & -0.2721 & -0.2461 & -0.2238 & -0.2152 & -0.2057 & -0.1954 & -0.1890 & -0.1828 & -0.1833 \\
\hline Expected return & 0.2096 & 0.0683 & 0.0332 & 0.0273 & 0.0238 & 0.0221 & 0.0211 & 0.0206 & 0.0200 & 0.0195 & 0.0193 \\
\hline No. of assets & 1 & 39 & 38 & 40 & 41 & 39 & 40 & 38 & 37 & 38 & 39 \\
\hline Dual simplex iter. & 0 & 1912 & 2204 & 2639 & 2378 & 2480 & 2526 & 2926 & 3278 & 3349 & 3414 \\
\hline $\mathrm{CPU}$ & 0.156 & 1.185 & 1.404 & 2.137 & 1.669 & 2.340 & 1.874 & 2.745 & 3.463 & 4.087 & 4.149 \\
\hline$(1-\alpha)^{-1} \sum_{i=1}^{m} p_{i} R_{i}$ & 0.0000 & 0.5068 & 0.4899 & 0.4969 & 0.5127 & 0.5193 & 0.5279 & 0.5379 & 0.5441 & 0.5502 & 0.5497 \\
\hline No. of non-zero $R_{i}$ & 0 & 388 & 384 & 379 & 383 & 380 & 383 & 383 & 383 & 384 & 391 \\
\hline \multicolumn{12}{|c|}{$\alpha=0.75$} \\
\hline \multicolumn{12}{|c|}{ Var. $=4189$, Cons. $=4021$, Nonz. $=349555$} \\
\hline CVaR & -23.6607 & -0.8647 & -0.3461 & -0.3206 & -0.3151 & -0.3140 & -0.3131 & -0.3128 & -0.3127 & -0.3126 & -0.3126 \\
\hline VaR & -23.6607 & -0.2573 & -0.0138 & 0.0000 & 0.0000 & 0.0000 & 0.0000 & 0.0000 & 0.0000 & 0.0000 & 0.0000 \\
\hline Expected return & 0.2096 & 0.1077 & 0.0282 & 0.0205 & 0.0178 & 0.0168 & 0.0157 & 0.0152 & 0.0150 & 0.0144 & 0.0142 \\
\hline No. of assets & 1 & 34 & 52 & 25 & 26 & 27 & 27 & 27 & 27 & 27 & 27 \\
\hline Dual simplex iter. & 0 & 3420 & 4191 & 4156 & 3904 & 3551 & 3961 & 4015 & 4885 & 6022 & 6058 \\
\hline $\mathrm{CPU}$ & 0.171 & 1.326 & 2.090 & 2.496 & 2.683 & 2.012 & 3.416 & 2.854 & 5.023 & 11.856 & 9.235 \\
\hline$(1-\alpha)^{-1} \sum_{i=1}^{m} p_{i} R_{i}$ & 0.0000 & 0.6074 & 0.3323 & 0.3206 & 0.3151 & 0.3140 & 0.3131 & 0.3128 & 0.3127 & 0.3126 & 0.3126 \\
\hline No. of non-zero $R_{i}$ & 0 & 1089 & 723 & 554 & 596 & 549 & 453 & 489 & 553 & 478 & 557 \\
\hline \multicolumn{12}{|c|}{$\alpha=0.50$} \\
\hline \multicolumn{12}{|c|}{ Var.$=4189$, Cons.$=4021$, Nonz.$=349555$} \\
\hline CVaR & -23.6607 & -0.7286 & -0.3386 & -0.1802 & -0.1631 & -0.1586 & -0.1574 & -0.1569 & -0.1564 & -0.1564 & -0.1563 \\
\hline VaR & -23.6607 & 0.0454 & 0.0107 & 0.0000 & 0.0000 & 0.0000 & 0.0000 & 0.0000 & 0.0000 & 0.0000 & 0.0000 \\
\hline Expected return & 0.2096 & 0.1480 & 0.0794 & 0.0310 & 0.0226 & 0.0189 & 0.0176 & 0.0166 & 0.0152 & 0.0149 & 0.0142 \\
\hline No. of assets & 1 & 20 & 41 & 47 & 25 & 26 & 26 & 27 & 27 & 27 & 27 \\
\hline Dual simplex iter. & 0 & 4176 & 4715 & 5400 & 5031 & 4401 & 4310 & 4756 & 5611 & 6899 & 8019 \\
\hline $\mathrm{CPU}$ & 0.171 & 1.185 & 1.622 & 2.636 & 2.418 & 1.934 & 2.277 & 3.042 & 4.820 & 9.703 & 13.104 \\
\hline$(1-\alpha)^{-1} \sum_{i=1}^{m} p_{i} R_{i}$ & 0.0000 & 0.7741 & 0.3493 & 0.1802 & 0.1631 & 0.1586 & 0.1574 & 0.1569 & 0.1564 & 0.1564 & 0.1563 \\
\hline No. of non-zero $R_{i}$ & 0 & 1729 & 1806 & 1112 & 546 & 346 & 547 & 547 & 553 & 553 & 557 \\
\hline
\end{tabular}


All the above computational experiments were conducted on a laptop with Intel@ Core 2 Duo T9300 processor running at $2.5 \mathrm{GHz}$ and with $4 \mathrm{~GB}$ RAM. For the implementation of $\mathbf{C V}$ and $\mathbf{E}$ _CV models, the AMPL programming language and the CPLEX v.11 solver (with the default settings) were applied.

\section{CONCLUSIONS}

The portfolio approach presented in this paper has allowed the two popular in financial engineering percentile measures of risk, value-at-risk $(V a R)$ and conditional value-atrisk $(C V a R)$ to be applied. The computational experiments show that the proposed solution approach based on linear programming models provides the decision maker with a simple tool for evaluating the relationship between the expected and the worstcase portfolio return. The decision maker can assess the value of portfolio return and the risk level, and can decide how to invest in a real life situation comparing with the ideal (optimal) portfolio solutions. A risk-aversive decision maker wants to maximize the conditional value-at-risk. Since the amount by which losses in each scenario exceed $V a R$ has been constrained of being positive, the presented models try to increase $V a R$ and hence positively impact the objective functions. However, large increases in $V a R$ may result in more historic portfolios (scenarios) with tail return, counterbalancing this effect. The concave efficient frontiers illustrate the trade-off between the conditional value-at-risk and the expected return of the portfolio. In all cases the CPU time increases when the confidence level decreases. The number of securities selected for the optimal portfolio for both the models varies between 1 and more than 50 assets. Those numbers show very little dependence on the confidence level $\alpha$ and the size of historical portfolio used as an input data. However, for the weighted-sum program, the weight parameter $\lambda$ does have an influence on the number of stocks selected for the optimal portfolio.

\section{ACKNOWLEDGMENTS}

The author is grateful to an anonymous reviewer for reading the manuscript very carefully and providing constructive comments which helped to substantially improve this paper.

This work has been partially supported by the Polish Ministry of Science and Higher Education grant for PhD Research \#N N519 405934 and by AGH grant.

\section{REFERENCES}

Alexander, G.J., Baptista, A.M., 2002. Economic implications of using mean-VaR model for portfolio selection: A comparision with mean-variance analysis. Journal of Economic and Dynamics Control, Vol. 26, 1159-1193.

Alexander, G.J., Baptista, A.M., 2004. A Comparison of VaR and CVaR Constraints on Portfolio Selection with the Mean-Variance Model. Management Science, Vol. 50(9), 1261-1273. 
Aliprantis, C.D., Brown, D.J., Werner, J., 2000. Minimum-cost portfolio insurance. Journal of Economic Dynamics and Control, Vol. 24, 1703-1719.

Aliprantis, C.D., Polyrakis, Y.A., Tourky, R., 2002. The cheapest hedge. Journal of Mathematical Economics, Vol. 37(4), 269-295.

Anagnostopoulos, K.P., Mamanis, G., 2010. A portfolio optimization model with three objectives and discrete variables. Computers and Operations Research, Vol. 37, 1285-1297.

Artzner, P., Delbaen, F., Eber, J.M., Heath, D., 1999. Coherent measures of risk. Mathematical Finance, Vol. 9, 203-228.

Bai, Z.D., Liu, H.X., Wong, W.K., 2009a. On the Markowitz mean-variance analysis of selffinancing portfolios. Risk and Decision Analysis, Vol. 1(1), 35-42.

Bai, Z.D., Liu, H.X., Wong, W.K., 2009b. Enhancement of the applicability of Markowitz's portfolio optimization by utilizing random matrix theory. Mathematical Finance, Vol. 19(4), 639-667.

Basak, S., Shapiro, A., 2001. Value-at-risk-based risk management: Optimal policies and assets prices. Review Financial Studies, Vol. 14, 371-405.

Basle Committee on Banking Supervision, 1996. Amendment to the capital accord to incorporate market risk. Basle Committee on Banking Supervision, www.bis.org.

Basle Committee on Banking Supervision, 2003. The new Basel capital accord. Basle Committee on Banking Supervision, www.bis.org.

Benati, S., 2003. The optimal portfolio problem with coherent risk measure constraints. European Journal of Operational Research, Vol. 150, 572-584.

Benati, S., Rizzi, R., 2007. A mixed integer linear programming formulation of the optimal mean/Value-at-Risk portfolio problem. European Journal of Operational Research, Vol. $176,423-434$.

Biglova, A.S., Ortobelli, S., Rachev, S., Stoyanov, S., 2004. Different approaches to risk estimation in portfolio theory. Journal of Portfolio Management, Vol. 31(1), 103-112.

Brennan, M.J., Solanki, R., 1981. Optimal portfolio insurance. Journal of Financial and Quantitative Analysis, Vol. 16(3), 279-300.

Cai, X., Teo, K.-L., Yang, X., Zhou, X.Y., 2000. Portfolio optimization under a minimax rule. Management Science, Vol. 46(7), 957-972.

Chahar, K., Taaffe K., 2009. Risk averse demand selection with all-or-nothing orders. Omega, Vol. 37, 996-1006.

Chance, D.M., 2004. An Introduction to Derivatives and Risk Management. 6th ed. Southwestern, Mason, OH, USA.

Chen, C., Kwon, R.H., 2010. Robust portfolio selection for index tracking. Computers and Operations Research, Chen C,Kwon RH.(2010),doi:10.1016/j.cor.2010.08.019.

Chateauneuf, A.F, Maccheroni, M., Marinacci, M., Tallon, J.-M., 2005. Monotone continuous multiple priors. Economic Theory, Vol. 26(4), 973-982.

Ding, Y., 2006. Portfolio selection under maximum minimum criterion. Quality and Quantity, Vol. 40, 457-468.

Esch, L., Kieffer, R., Lopez, T., Berbé, C., Damel, P., Debay, M., Hannosset, J.-F., 2005. Asset and Risk Management. Risk Oriented Finance. John Wiley \& Sons.

Gajdos, T., Tallon, J.-M., Vergnaud, J.-C., 2004. Decision making with imprecise probabilistic information. Journal of Mathematical Economics, Vol. 40, 647-681.

Garlappi, L., Uppal, R., Wang, T., 2007. Portfolio selection with parameter and model uncertainty: A multi-prior approach. Review of Financial Studies, Vol. 20(1), 41-81.

Gilboa, I., Schmeidler, D., 1989. Maximin expected utility with non-unique prior. Journal of Mathematical Economics, Vol. 18(2), 141-153. 
Gulpinar, N., Rustem, B., 2007. Worst-case robust decision for multi-period mean-variance portfolio optimization. European Journal of Operational Research, Vol. 183(3), 9811000.

Holton, G., 2003. Value-at-Risk: Theory and Practice. Academic Press.

Hull, J.C., 2003. Options, Futures and Other Derivatives. Prentice-Hall, Upple Saddle River, NJ, USA.

Jorion, P., 2006. Value at Risk: The New Benchmark for Managing Financial Risk. 3rd ed. McGraw-Hill.

Kahneman, D., Tversky, A., 1979. Prospect theory: An analysis of decision under risk. Econometrica, Vol. 47(2), 263-291.

Katsikis, V.N., 2007. Computational methods in portfolio insurance. Applied Mathematics and Computation, Vol. 189, 9-22.

Konno, H., 1990. Pricewise linear risk function and portfolio optimization. Journal of the Operations Research Society of Japan, Vol. 33(2), 139-156.

Konno, H., Yamazaki, H., 1991. Mean-absolute deviation portfolio optimization model and its applications to Tokyo stock market. Management Science, Vol. 37(5), 519-531.

Krokhmal, P., Palmquist, J., Uryasev, S., 2002. Portfolio optimization with conditional valueat-risk objective and constraints. Journal of Risk, Vol. 4, 43-68.

Leland, H.E., 1980. Who should buy portfolio insurance? The Journal od Finance, Vol. 35(2), 581-594.

Leung, P.L., Wong, W.K., 2008. On testing the equality of the multiple Sharpe ratios, with application on the evaluation of iShares. Journal of Risk, Vol. 10(3), 1-16.

Linsmeier, T.J., Pearson, N.D., 2000. Value at risk. Financial Analysts Journal, Vol. 56, $47-67$.

Mansini, R., Ogryczak, W., Speranza, M.G., 2003a. On LP solvable models for portfolio selection. Informatica, Vol. 14(1), 37-62.

Mansini, R., Ogryczak, W., Speranza, M.G.,, 2003b. LP solvable models for portfolio optimization: A classification and computational comparison. IMA Journal of Management Mathematics, Vol. 14, 187-220.

Mansini, R., Ogryczak, W., Speranza, M.G., 2007. Conditional value at risk and related linear programming models for portfolio optimization. Annals of Operations Research, Vol. 152, 227-256.

Markowitz, H.M., 1952. Portfolio selection. Journal of Finance, Vol. 7, 77-91.

Markowitz, H.M., 1959. Portfolio Selection: Efficient Diversification of Investments. A John Wiley \& Sons, Inc., Publication, New York, USA.

Markowitz, H.M., 1991. Portfolio Selection. 2nd ed. Blackwell, Cambridge, Massachusetts, USA.

Markowitz, H.M., 1997. Portfolio Selection: Efficient Diversification of Investments. Second edition. Blackwell Publishers, Inc., Malden, Mass., USA.

Markowitz, H.M., van Dijk, E.L., 2003. Single-period mean-variance analysis in a changing world. Financial Analysts Journal, Vol. 59, 30-44.

Ogryczak, W., 2000. Multiple criteria linear programming model for portfolio selection. Annals of Operations Research, Vol. 97, 143-162.

Polak, G.G., Rogers, D.F., Sweeney, D.J., 2010. Risk Management Strategies via minimax portfolio optimization. European Journal of Operational Research, Vol. 207, 409-419.

Pflug, G., 2000. Some remarks on the value-at-risk and the conditional value-at-risk. In: Uryasev S., ed.) Probabilistic constrained optimization: methodology and applications. Kluwer Academic Publishers, pp. 272-281.

Rockafellar, R.T., Uryasev, S., 2000. Optimization of conditional value-at-risk. The Journal of Risk, Vol. 2(3), 21-41. 
Rockafellar, R.T., Uryasev, S., 2002. Conditional value-at-risk for general loss distributions. The Journal of Banking and Finance, Vol. 26, 1443-1471.

Sarykalin, S., Serraino, G., Uryasev, S., 2008. Value-at-Risk vs. Conditional Value-at-Risk in Risk Management and Optimization. In:Z-L. Chen, S. Raghavan, P. Gray, Eds.) Tutorials in Operations Research, INFORMS Annual Meeting, Washington D.C., USA, October 12-15, 2008.

Sawik B.,, 2008. A Three Stage Lexicographic Approach for Multi-Criteria Portfolio Optimization by Mixed Integer Programming. Przeglad Elektrotechniczny, Vol. 84(9), 108112.

Sawik, B., 2009a. Lexicographic and Weighting Approach to Multi-Criteria Portfolio Optimization by Mixed Integer Programming. Chapter in: Lawrence K.D., Kleinman G., eds.) Applications of Management Science, Vol. 13, Financial Modeling Applications and Data Envelopment Applications, Emerald Group Publishing Limited, U.K., USA, pp. 3-18.

Sawik, B., 2009b. A Reference Point Approach to Bi-Objective Dynamic Portfolio Optimization. Decision Making in Manufacturing and Services, Vol. 3(1-2), 74-85.

Sawik, B., 2010. Selected Multi-Objective Methods for Multi-Period Portfolio Optimization by Mixed Integer Programming. Chapter in: Lawrence K.D., Kleinman G., eds.) Applications of Management Science, Volume 14, Applications in Multi-Criteria Decision Making, Data Envelopment Analysis and Finance, Emerald Group Publishing Limited, U.K., USA, pp. 3-34.

Schrage, L., 2001. Optimization modeling with LINGO. LINDO Systems, Inc., Chicago, Illinois, USA.

Sharpe, W.F., 1963. A simplified model for portfolio analysis. Management Science, Vol. 9(2), 277-293.

Sharpe, W.F., 1967. A linear programming algorithm for mutual fund portfolio selection. Management Science, Vol. 13(7), 499-510.

Sharpe, W.F., 1971. A linear programming approximation for the general portfolio analysis problem. Journal of Financial and Quantitative Analysis, Vol. 6(5), 1263-1275.

Speranza, M.G., 1993. Linear programming models for portfolio optimization. Finance, Vol. $14,107-123$.

Stone, B.K. „1973. A linear programming formulation of the general portfolio selection problem. Journal of Financial and Quantitative Analysis, Vol. 8(4), 621-636.

Teo, K.L., Yang, X.Q., 2001. Portfolio selection problem with minimax type risk function. Annals of Operations Research, Vol. 101, 333-349.

Uryasev, S., 2000. Conditional value-at-risk: optimization algorithms and applications. Financial Engineering News, Issue 14, February 2000.

Yitzhaki, S., 1982. Stochastic dominance, mean variance, and Gini's mean difference. The American Economic Review, Vol. 71(1), 178-185.

Yiu, K.F.C., 2004. Optimal portfolios under a value-at-risk constraint. Journal of Economic and Dynamics Control, Vol. 28, 1317-1334.

Young, M.R., 1998. A minimax portfolio selection rule with linear programming solution. Management Science, Vol. 44(5), 673-683. 